\title{
LUZ E TEMPERATURA NA GERMINAÇÃO DE SEMENTES DE PIMENTA LONGA (Piper hispidinervum) E PIMENTA-DE-MACACO (Piper aduncum) ${ }^{1}$
}

\author{
CELSO LUIS BERGO², ROSEMEIRE CARVALHO DA SILVA ${ }^{3}$, OSVALDO DE CASTRO OHLSON ${ }^{4}$, \\ LUIZ ANTONIO BIASI ${ }^{5}$, MARISTELA PANOBIANCO ${ }^{6}$
}

\begin{abstract}
RESUMO - As espécies Piper hispidinervum e Piper aduncum destacam-se como produtoras de óleos essenciais ricos em compostos de interesse às indústrias de perfumaria e produtos fitossanitários, como o safrol e dilapiol. Essas espécies encontram-se em processo de domesticação e estudos sobre o processo germinativo de suas sementes são escassos. Assim, objetivou-se com o presente trabalho avaliar a viabilidade de sementes de $P$. hispidinervum e $P$. aduncum, buscando determinar um protocolo eficiente para a realização do teste de germinação para cada espécie estudada. $O$ trabalho foi conduzido no período de julho a agosto de 2008, sendo as sementes submetidas a diferentes combinações de temperatura e de luz: $20^{\circ} \mathrm{C}$ e $25{ }^{\circ} \mathrm{C}$ sob luz branca e difusa; e $20-30{ }^{\circ} \mathrm{C}$ alternando escuro $(16 \mathrm{~h})$ e claro $(8 \mathrm{~h})$, totalizando cinco tratamentos. $\mathrm{O}$ tratamento utilizando a temperatura de $25{ }^{\circ} \mathrm{C}$ com incidência de luz branca foi o que produziu melhores resultados, com maiores valores de porcentagem e velocidade de germinação sendo, portanto, indicado para avaliação da qualidade fisiológica das sementes de pimenta longa e pimenta-de-macaco.
\end{abstract}

Termos para indexação: Piperácea, luz, temperatura, qualidade fisiológica.

\section{LIGHT AND TEMPERATURE IN THE SEED GERMINATION OF LONG PEPPER (Piper hispidinervum) AND MONKEY PEPPER (Piper aduncum)}

\begin{abstract}
The species Piper hispidinervum and Piper aduncum stand out as producers of essential oils, rich in compounds, such as saffrol and dillapiol, which are of interest to the fragrance and pesticide industries. These species are being domesticated and studies about their seed germination process are scarce and the aim of this study was to develop an efficient protocol for germination tests with which to evaluate seed viability in $P$. hispidinervum and $P$. aduncum. The study was carried out in July and August, 2008, when the seeds were submitted to different combinations of temperature and light: $20^{\circ} \mathrm{C}$ and $25^{\circ} \mathrm{C}$ with diffuse, white light; and $20-30{ }^{\circ} \mathrm{C}$ with alternating dark $(16 \mathrm{~h})$ and light $(8 \mathrm{~h})$ periods, totaling 5 treatments. The treatment with $25^{\circ} \mathrm{C}$ and white light gave the best results in terms of higher percentages and germination rates, and therefore, these conditions are recommended for evaluating seed physiological quality of long pepper and monkey pepper.
\end{abstract}

Index terms: Piperaceae, light, temperature, physiological quality.

\footnotetext{
${ }^{1}$ Submetido em 07/04/2009. Aceito para publicação em 11/03/2010.

${ }^{2}$ Eng. Agr. M.Sc., Pesquisador, Embrapa Acre, Caixa Postal 321, CEP: 69914-220 Rio Branco, AC, Brasil. celsobergo@yahoo.com.br.

${ }^{3}$ Estudante de Graduação em Agronomia, Universidade Federal do Paraná (UFPR), Caixa Postal 19061, CEP: 81531-990 - Curitiba, PR, Brasil,
}

e-mail: mericazinha@yahoo.com.br. ${ }^{4}$ Eng. Agr. Mestrando UFPR, Cx. Postal 19061, 81531-990 - Curitiba, PR,
Brasil. osvaldo@terra.com.br.

${ }^{5}$ Eng. Agr., D. Sc., Dep. Fitotecnia e Fitossanitarismo, UFPR, Professor, Cx. Postal 19061, 81531-990 - Curitiba, PR, Brasil.biasi@ufpr.br 


\section{INTRODUÇÃO}

A crescente demanda por produtos naturais tem impulsionado as pesquisas em busca de recursos ainda subutilizados da flora brasileira. Neste sentido, podem-se ressaltar as plantas medicinais, aromáticas e condimentares, que possuem em sua composição compostos úteis para formulação de medicamentos, produtos alimentícios, perfumarias, cosméticos e produtos fitossanitários. Dentre as espécies aromáticas, encontram-se aquelas pertencentes à família Piperaceae, onde Piper hispidinervum e Piper aduncum se destacam.

A espécie $P$. hispidinervum, conhecida como pimenta longa, apresenta potencial para produção de óleo essencial com rendimento médio entre 3 a $4 \%$ em relação à matéria seca, tendo como principal constituinte o safrol (88 a 95\%), um componente químico aromático capaz de gerar por transformações químicas a heliotropina e o butóxido de piperolina, utilizados, respectivamente, como matériaprima na indústria de cosméticos e como agente sinergístico dos inseticidas naturais à base de piretrum (Wadt, 2001).

Com relação à espécie $P$. aduncum, popularmente chamada de pimenta-de-macaco, a substância de interesse presente no seu óleo essencial é o dilapiol (Maia et al., 1998), o qual tem sido considerado um produto natural para controle de insetos e fitopatógenos em culturas tradicionalmente cultivadas (Fazolin et al., 2006).

Apesar de se ter conhecimento sobre o potencial dessas espécies a exemplo da $P$. hispidinervum que se destaca como uma possível substituta da canela-sassafrás (Ocotea odorifera nees) na produção de safrol, as mesmas ainda encontram-se em processo de domesticação, sendo que informações sobre sua reprodução e processo germinativo são escassas e necessárias para dar continuidade às pesquisas e investimentos no seu cultivo.

Araújo et al. (2003), estudando o potencial reprodutivo dessas espécies, relataram as características biométricas de suas espiguetas (número por planta; comprimento e massa), o número de sementes por espigueta e o peso de 1000 sementes, verificando os seguintes resultados: para $P$. hispidinervum, número de espiguetas por plantas (872), comprimento da espigueta $(9,41 \mathrm{~cm})$, peso da espigueta $(2,48 \mathrm{~g})$, número de sementes por espigueta $(1821)$ e peso de 1000 sementes $(0,143 \mathrm{~g})$; para $P$. aduncum, número de espiguetas por plantas (1072), comprimento da espigueta $(10,3 \mathrm{~cm})$, peso da espigueta $(1,90 \mathrm{~g})$, número de sementes por espigueta (1207) e peso de 1000 sementes $(0,193 \mathrm{~g})$.

Segundo Cavalcante et al. (2002) para a formação de mudas no atual estágio de domesticação dessas espécies são necessárias de três a quatro sementes por recipiente, sendo que após as plântulas atingirem $2 \mathrm{~cm}$ de altura, recomenda-se efetuar o desbaste deixando-se somente uma plântula, que posteriormente será transplantada para o campo. Considerando-se uma densidade de 13.333 plantas ha $^{-1}(1,0 \times 0,75 \mathrm{~m})$ como a ideal para se alcançar o máximo de produção de biomassa das folhas, faz-se necessário um viveiro de tamanho equivalente a $160 \mathrm{~m}^{2}$ para produzi-las (Pimentel et al., 1998; Wadt e Pacheco, 2006). Assim, o conhecimento da viabilidade das sementes é importante para minimizar custos e reduzir o tempo para a formação das mudas.

Sabe-se que vários fatores do ambiente podem interferir na germinação da semente, como luz e temperatura. Segundo Carvalho e Nakagawa (2000) a luz é um agente natural de superação de dormência e não participa do processo germinativo; porém, outros autores como Marcos Filho (2005) consideram a luz, juntamente com a temperatura, água e oxigênio, fatores externos que interferem no processo. Sobre este aspecto destaca-se a pesquisa de Almeida (1999) com $P$. hispidinervum, que constatou fotoblastismo positivo para a espécie. A temperatura, por outro lado, influencia tanto na porcentagem quanto na velocidade de germinação, interferindo na velocidade de absorção da água e nas reações bioquímicas (Marcos Filho, 2005). Vários estudos têm demonstrado que a luz e a temperatura interferem na germinação da semente de diferentes espécies, como pode ser observado nos trabalhos de Stefanelo et al. (2006); Amato et al. (2007); Yamashita et al. (2008); Rego et al. (2009) e Zucareli et al. (2009).

Nas Regras para Análise de Sementes (Brasil, 1992), podem-se observar recomendações para a condução do teste de germinação de sementes de várias espécies, no entanto, constata-se escassez de informações para as espécies medicinais, aromáticas e condimentares. No caso específico das Piperáceas, observou-se ausência de descrição de metodologia.

Com o avanço dos estudos e comprovado potencial dessas espécies, espera-se um crescente interesse para sua exploração agrícola, o que justifica a necessidade de métodos padronizados para analisar a viabilidade de suas sementes. A definição desses métodos poderá contribuir para a melhor condução de viveiros destinados a produção de mudas para plantios comerciais.

Assim, objetivou-se com o presente trabalho avaliar a viabilidade de sementes de $P$. hispidinervum e $P$. aduncum, buscando determinar um protocolo eficiente 
para a realização do teste de germinação para cada uma das espécies estudadas.

\section{MATERIAL E MÉTODOS}

O trabalho foi conduzido no Laboratório de Análise de Sementes Oficial da Empresa Paranaense de Classificação de Produtos - CLASPAR, em Curitiba, no período de julho a agosto de 2008 .

As sementes da espécie $P$. hispdinervum foram obtidas de plantas pertencentes ao banco de germoplasma da Embrapa Acre, situada no município de Rio BrancoAC, sendo a coleta realizada em abril de 2008. Por outro lado, as sementes da espécie $P$. aduncum foram coletadas em fevereiro de 2008, em um remanescente de Floresta Ombrófila Densa Atlântica, pertencente à empresa Solar Paisagismo Ltda., localizada no município de Morretes PR.

Para a coleta e o preparo das sementes seguiu-se o procedimento descrito por Cavalcante et al. (2002), onde as espiguetas maduras foram coletadas manualmente e imersas por 24 horas em água, maceradas posteriormente em peneira de polietileno de 230 mash e lavadas até a completa retirada da mucilagem. Em seguida, as sementes foram secas sobre papel ao ar livre, em local sombreado e ventilado durante 72 horas, armazenadas em embalagens de vidro na cor âmbar, hermeticamente fechadas e mantidas em refrigerador a $10{ }^{\circ} \mathrm{C}$ até o início dos testes.

No laboratório foram realizadas as seguintes determinações:

Peso de mil sementes - conduzido de acordo com as prescrições estabelecidas nas Regras para Análise de Sementes (Brasil, 1992), utilizando-se oito subamostras de 100 sementes provenientes da porção "Semente Pura".

Teste de germinação - quatro subamostras cada qual com 100 sementes foram colocadas para germinar em caixas plásticas transparentes $(11,0 \times 11,0$ x 3,5 cm), sobre quatro folhas de papel filtro $6,5 \mathrm{~g}$, umedecidas com água na quantidade de 2,5 vezes a massa do substrato, mantidas em germinador, sendo combinados os fatores temperatura e luz, totalizando cinco tratamentos. As sementes foram incubadas a $20{ }^{\circ} \mathrm{C}$ e $25{ }^{\circ} \mathrm{C}$ sob luz branca (720 lux) e luz difusa (120 lux) em germinadores do tipo Mangelsdorf, e a $20-30{ }^{\circ} \mathrm{C}$, com presença de luz branca (670 lux) por 8 h a $30{ }^{\circ} \mathrm{C}$ e escuro por $16 \mathrm{~h}$ a $20^{\circ} \mathrm{C}$, em germinador do tipo CASPMATIC G40. A luz branca foi fornecida por lâmpadas fluorescentes disponíveis nos germinadores e a luz difusa foi obtida pelo envolvimento das caixas plásticas com folhas de papel celofane nas cores vermelha e azul, com o intuito de simular uma pequena clareira (Almeida, 1999). Para a determinação da intensidade luminosa foi utilizado um luxímetro digital marca ICEL/Manaus - LD 510. Na avaliação do teste de germinação utilizou-se como critério as Regras para Análise de Sementes (Brasil, 1992).

Índice de Velocidade de Germinação (IVG) conduzido para cada metodologia estudada nos testes de germinação, realizando-se avaliações das plântulas diariamente e no mesmo horário, a partir do surgimento das primeiras plântulas normais. O IVG foi calculado pela fórmula de Maguire (1962).

O delineamento experimental utilizado foi o inteiramente casualizado, com quatro repetições, sendo a comparação das médias realizada pelo teste de Tukey a $5 \%$ de probabilidade, utilizando-se o programa estatístico MSTAT, versão 2.11 (Nissen, 1993).

\section{RESULTADOS E DISCUSSÃO}

As espécies caracterizam-se pelo tamanho extremamente pequeno de suas sementes (Figura $1-\mathrm{A}$ ). A espécie $P$. hispidinervum apresentou peso de mil sementes de 0,172 $\mathrm{g}$, enquanto que para $P$. aduncum esse peso foi de 0,231 g. Dados semelhantes foram encontrados por Araújo et al. (2003) que relataram peso médio de mil sementes igual a 0,143 g e 0,193 g para $P$. hispidinervum e $P$. aduncum, respectivamente. As massas encontradas pelos autores citados são aproximadamente $16 \%$ menores que as obtidas neste trabalho, mas ambos os estudos mostraram uma massa superior das sementes de $P$. aduncum, de aproximadamente $34 \%$ quando comparada às de $P$. hispidinervum.

Deve-se ressaltar que Araújo et al. (2003) trabalharam com sementes de populações existentes no município de Rio Branco (AC), com $160 \mathrm{~m}$ de altitude, latitude 9 ${ }^{\circ} 58^{\prime} 22^{\prime \prime} \mathrm{S}$, longitude $67^{\circ} 48^{\prime} 40^{\prime}$ ' $\mathrm{W}$, com precipitação anual entre 1800 e $1900 \mathrm{~mm}$ e temperatura média de $25{ }^{\circ} \mathrm{C}$. As sementes $P$. hispidinervum, utilizadas neste trabalho, originaram-se desta mesma localidade; porém, as da espécie $P$. aduncum foram coletadas em Morretes - PR, em uma altitude que não ultrapassa $100 \mathrm{~m}$, latitude $25^{\circ} 25^{\prime}, 51,3^{\prime \prime}$ ' S e longitude $48^{\circ} 52^{\prime}$ $37,7^{\prime \prime} \mathrm{W}$, precipitação média anual em torno de $2000 \mathrm{~mm}$ e temperatura média também $25{ }^{\circ} \mathrm{C}$. Embora semelhantes no clima, trata-se de dois biomas diferentes. Portanto, a massa superior das sementes de $P$. aduncum em relação à $P$. hispidinervum é uma característica da própria espécie e não do seu local de origem ou cultivo. 

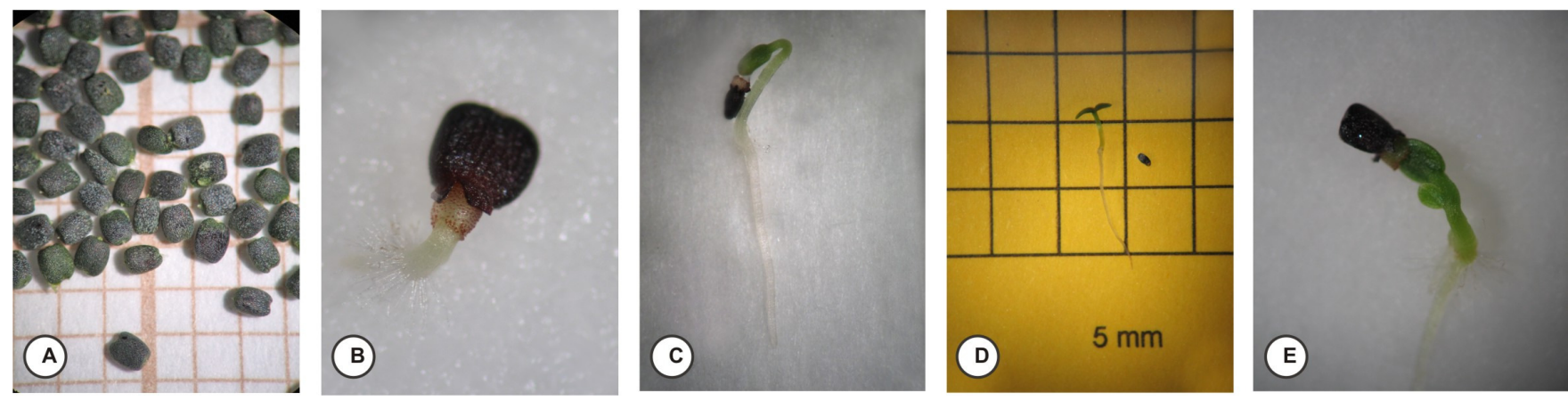

FIGURA 1. Sequência do processo germinativo das sementes de Piper sp: sementes de Piper sp. sobre papel milimetrado, ampliadas 20X (A); semente em início de germinação (B); plântula prestes a liberar o tegumento (C); plântula considerada normal com tegumento ao lado (D) e plântula considerada anormal (E).

Na Tabela 1 encontram-se os resultados de germinação (G) e do Índice de Velocidade de Germinação (IVG) das sementes de $P$. hispidinervum. Pode-se verificar que não houve diferenças significativas entre os tratamentos para os porcentuais de germinação $(G)$, independentemente da temperatura ou da incidência de luz branca ou difusa. As porcentagens variaram de $87 \%$ (mínimo) para o tratamento $25^{\circ} \mathrm{C}$, luz difusa, até o máximo de $96 \%$ para o tratamento 25 ${ }^{\circ} \mathrm{C}$ na presença de luz branca.

TABELA 1. Valores médios de Germinação (G) e Índice de Velocidade de Germinação (IVG) de sementes de $P$. hispidinervum, sob diferentes combinações de temperatura e luz.

\begin{tabular}{lcc}
\hline \multirow{2}{*}{ Tratamentos } & \multicolumn{2}{c}{ P. hispidinervum } \\
\cline { 2 - 3 } & $\mathrm{G}(\%)$ & IVG \\
\hline $25^{\circ} \mathrm{C}$ - luz branca & $96 \mathrm{a}^{1}$ & $7,05 \mathrm{a}$ \\
$25^{\circ} \mathrm{C}$ - luz difusa & $87 \mathrm{a}$ & $5,92 \mathrm{~b}$ \\
$20-30{ }^{\circ} \mathrm{C}$ & $89 \mathrm{a}$ & $5,38 \mathrm{bc}$ \\
$20{ }^{\circ} \mathrm{C}$ - luz branca & $93 \mathrm{a}$ & $5,31 \mathrm{bc}$ \\
$20^{\circ} \mathrm{C}$ - luz difusa & $92 \mathrm{a}$ & $4,67 \quad \mathrm{c}$ \\
\hline C.V.(\%) & 7,06 & 7,49 \\
\hline
\end{tabular}

${ }^{1}$ Médias seguidas pela mesma letra na coluna não diferem entre si pelo teste de Tukey, a $5 \%$ de probabilidade.

Entretanto, quando se observa o IVG, o tratamento a $25{ }^{\circ} \mathrm{C}$ utilizando-se luz branca foi superior aos demais, proporcionando germinação mais rápida. Observa-se ainda que o IVG dessa espécie é influenciado tanto pela temperatura quanto pelo tipo de luz incidente, verificando que de fato tratamentos com maiores temperaturas e incidência de luz branca resultaram em maiores índices de velocidade de germinação.

Para os tratamentos com sementes expostas a uma menor temperatura $\left(20^{\circ} \mathrm{C}\right)$, o índice de velocidade de germinação foi estatisticamente menor (Tabela 1), e esta diminuição foi mais acentuada quando o tratamento foi submetido à incidência de luz difusa, sugerindo que em condições de temperatura inferior a $25{ }^{\circ} \mathrm{C}$, a incidência de luz difusa influencia negativamente na germinação das sementes de P. hispidinervum. Almeida (1999) avaliando o efeito da luz e temperatura na germinação de sementes de $P$. hispidinervum observou maior porcentagem de germinação sob as luzes vermelha e branca, com temperatura de $25^{\circ} \mathrm{C}$, obtendo-se $73 \%$ e $71 \%$ de germinação, respectivamente, sugerindo ser uma espécie fotoblástica positiva.

Assim, para esta espécie, a luz parece oferecer maior influência no IVG, visto que os resultados apontaram para maior rapidez de germinação quando as sementes foram submetidas à luz branca e temperatura constante de $25^{\circ} \mathrm{C}$.

De fato, Pimentel e Pinheiro (2000) caracterizando habitats naturais de $P$. hispidinervum no município de Brasiléia, no Acre, constataram que a maioria desses habitats surge em áreas cultivadas com arroz, feijão, milho e pastagens abandonadas e degradadas e que em nenhum dos habitats visitados evidenciou-se a presença da pimenta longa em áreas de florestas primária e secundária, confirmando, portanto, a alta exigência da planta em relação à luz.

Na Tabela 2 encontram-se os resultados de germinação (G) e Índice de Velocidade de Germinação (IVG) das sementes de $P$. aduncum. 
TABELA 2. Valores médios de Germinação (G) e Î́ndice de Velocidade de Germinação (IVG) de sementes de $P$. aduncum, sob diferentes condições de temperatura e luz.

\begin{tabular}{|c|c|c|}
\hline \multirow{2}{*}{ Tratamentos } & \multicolumn{2}{|c|}{ P. aduncum } \\
\hline & $\mathrm{G}(\%)$ & IVG \\
\hline $25^{\circ} \mathrm{C}$ - luz branca & $89 a^{1}$ & $5,35 \mathrm{a}$ \\
\hline $25^{\circ} \mathrm{C}$ - luz difusa & $88 \mathrm{a}$ & $4,98 \mathrm{ab}$ \\
\hline $20-30^{\circ} \mathrm{C}$ & $88 \mathrm{a}$ & 4,75 \\
\hline $20{ }^{\circ} \mathrm{C}$ - luz branca & $80 \mathrm{ab}$ & 3,95 \\
\hline $20{ }^{\circ} \mathrm{C}$ - luz difusa & $75 \mathrm{~b}$ & 3,04 \\
\hline C.V.(\%) & 4,51 & 4,33 \\
\hline
\end{tabular}

${ }^{1}$ Médias seguidas pela mesma letra na coluna não diferem entre si pelo teste de Tukey, a $5 \%$ de probabilidade.

Para esta espécie pode-se verificar que houve diferença significativa entre os tratamentos tanto para a porcentagem quanto a velocidade de germinação, destacando-se aqueles sob maiores temperaturas. Os maiores porcentuais de germinação $(\mathrm{G} \%)$ foram obtidos nos tratamentos submetidos às temperaturas de $25{ }^{\circ} \mathrm{C} \mathrm{e}$ 20-30 ${ }^{\circ} \mathrm{C}$. Sob estas condições a influência do tipo de luz incidente, branca ou difusa, foi indiferente. Observa-se pelo IVG uma influência tanto da temperatura quanto do tipo de luz incidente. Para esta variável há uma relação direta entre temperatura e velocidade de germinação, onde os tratamentos submetidos às maiores temperaturas (25 ${ }^{\circ} \mathrm{C}$ e $20-30{ }^{\circ} \mathrm{C}$ ) foram os que mostraram maiores índices de germinação.

Também para essa espécie, a exemplo da $P$. hispidinervum (Tabela 1), sementes submetidas aos tratamentos com menor temperatura $\left(20^{\circ} \mathrm{C}\right)$ resultaram num menor índice de velocidade de germinação, e esta diminuição foi mais acentuada quando as sementes foram submetidas à incidência de luz difusa, sugerindo que em condições de temperatura inferior a $25^{\circ} \mathrm{C}$, a menor incidência de luz influencia negativamente na germinação das sementes de $P$. aduncum. Freitas et al. (2006) estudando também a germinação de $P$. aduncum, observaram maior porcentagem de germinação com a temperatura de $27{ }^{\circ} \mathrm{C}$, confirmando que a espécie requer temperaturas mais altas para efetuar o processo germinativo.

Diante do exposto, observa-se que tanto para a espécie $P$. hispidinervum quanto para a $P$. aduncum o fator temperatura exerce uma influência maior que a luz no processo germinativo de suas sementes. Os tratamentos com temperaturas mais elevadas foram os que proporcionaram os melhores resultados. A Figura 2 ilustra graficamente esta influência na germinação de ambas as espécies.

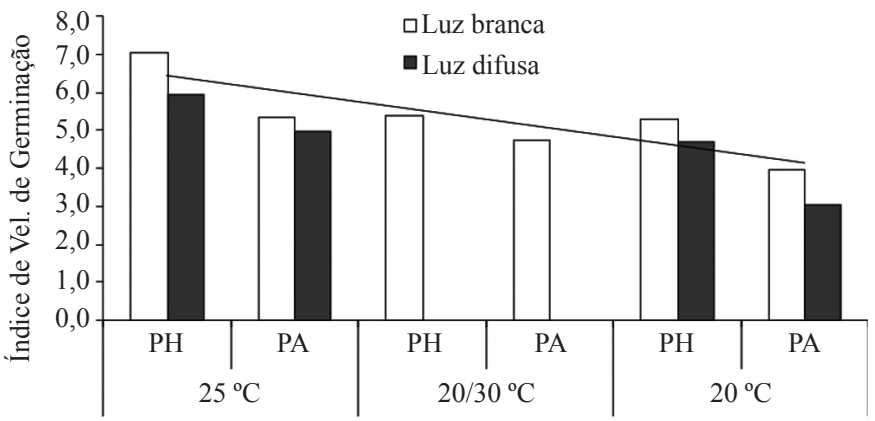

FIGURA 2. Variação do IVG das sementes de $P$. hispidinervum (PH) e P. aduncum (PA) sob diferentes combinações de temperatura e incidência de luz.

A definição de datas para a avaliação do teste de germinação é importante para padronizar os procedimentos de avaliação da qualidade fisiológica das sementes dessas espécies.

A sequência do processo germinativo das sementes de Piper sp. pode ser observada na Figura 1. A partir do $10^{\circ}$ dia para a $P$. hispidinervum e $14^{\circ}$ para $P$. aduncum observouse o início da germinação (Figura $1-\mathrm{B}$ ) com evolução para plântula com o tegumento ainda aderido às folhas cotiledonares (Figura $1-\mathrm{C}$ ) e, totalmente germinado com a liberação definitiva do tegumento (Figura $1-\mathrm{D}$ ) quando as plântulas já apresentavam um tamanho aproximado de 1 $\mathrm{cm}$, raiz primária totalmente desenvolvida, número elevado de pêlos absorventes e as folhas cotiledonares totalmente expostas, sendo consideradas como plântulas normais. Este critério de plântula normal está de acordo com as prescrições estabelecidas nas Regras para Análise de Sementes (Brasil, 1992). No final dos testes, observou-se a ocorrência de plântulas com tegumento retido (Figura $1-\mathrm{E}$ ) consideradas como plântulas anormais. Este detalhe morfológico foi o que mais gerou plântulas anormais, embora também tenha sido constatada a presença de plântulas com infecção primária, ou seja, estavam seriamente deterioradas devido à presença de fungos ou bactérias.

Como os maiores porcentuais de germinação foram alcançados com a temperatura $25{ }^{\circ} \mathrm{C}$ sob incidência de luz branca, na Figura 3 estão representados graficamente os resultados obtidos quando as sementes das duas espécies 
foram submetidas a este tratamento. Nesta figura observase que a produção de plântulas normais para a espécie $P$. hispidinervum ocorreu em sua maioria entre o $13^{\circ}$ e $14^{\circ}$ dia totalizando $91 \%$ da germinação, finalizando o processo no $21^{\circ}$ dia. Com relação à $P$. aduncum houve produção de maior número de plântulas normais no $17^{\circ}$ dia, com finalização do processo no $24^{\circ}$ dia.

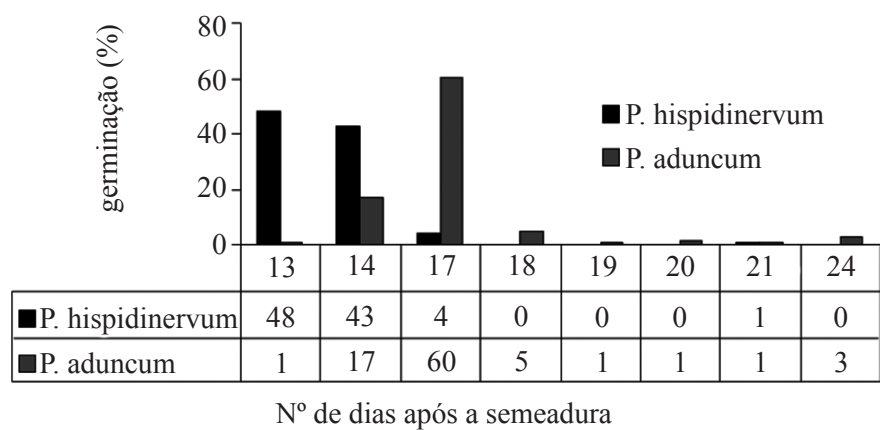

FIGURA 3. Valores de germinação de sementes de $\boldsymbol{P}$. hispidinervum e P. aduncum de acordo com o número de dias após a instalação do teste, quando submetidas ao tratamento: $25^{\circ} \mathrm{C}-$ luz branca.

\section{CONCLUSÕES}

- O tratamento $25{ }^{\circ} \mathrm{C}$ sob luz branca apresenta melhores resultados, tanto para porcentagem quanto para velocidade de germinação.

- Para a espécie P. hispidinervum, a primeira e última contagem do teste de germinação devem ser realizadas, respectivamente, no $14^{\circ}$ e $21^{\circ}$ dia após semeadura.

- Para a espécie P. aduncum, a primeira e última contagem do teste de germinação devem ser realizadas no $17^{\circ}$ e $24^{\circ}$ dias após a semeadura.

\section{REFERÊNCIAS}

ALMEIDA, M. de C. Banco de sementes e simulação de clareiras na germinação de Pimenta longa (Piper hispidinervium C.DC.). 1999. 60f. Tese (Mestrado em Agronomia) - Curso de Pós-Graduação em Agronomia, Universidade Federal do Acre. Rio Branco, 1999.

AMATO, A.L.P.; MAIA, F.C.; MAIA, M.S.; CAETANO, L.S.; SIMONI, S.B.; CONTOS, L.; FILHO, R.M.B. Estabelecimento de condições de luz e temperatura para germinação de sementes de amendoim forrageiro. Revista
Brasileira de Sementes, v.29, n.3, p.54-59, 2007.

ARAÚJO, J.S. de; MENDONÇA, H.A. de; SOUSA, J.A. de; BASTOS, R.M. Caracterização e avaliação da coleção de pimenta longa da Embrapa Acre. In: CONGRESSO BRASILEIRO DE MELHORAMENTO DE PLANTAS, 2., 2003, Porto Seguro. Melhoramento e qualidade de vida: Anais... Porto Seguro: SBMP, 2003.

BRASIL. Ministério da Agricultura e Reforma Agrária. Secretaria Nacional de Defesa Agropecuária. Departamento Nacional de Defesa Vegetal. Coordenação de Laboratório Vegetal. Regras para análise de sementes. Brasília, DF, 1992. 365p.

CARVALHO, N.M. de; NAKAGAWA, J. Semente: ciência, tecnologia e produção. 4.ed. Jaboticabal: FUNEP, 2000. $588 \mathrm{p}$.

CAVAlCANTE, M. de J.B., (Ed). Cultivo da pimenta longa (Piper hispidinervum) na Amazônia Ocidental. Rio Branco: Embrapa Acre, 2002. 29p. (Embrapa Acre. Sistemas de Produção, 1).

FAZOLIN, M.; ESTRELA, J.L.V.; CATANI, V.; COSTA, C.R. da. Potencialidades da Pimenta-de-macaco (Piper aduncum L.): características gerais e resultados de pesquisa. Rio Branco, AC: Embrapa Acre, 2006. 53p. il. color. (Embrapa Acre. Documentos, 103).

FREITAS, J.M.N.; CASTRO, D.S.; LOBATO, A.K.S.; CAVALHO,K.S.; OLIVEIRA NETO,C.F.; COSTA, C.L. Germinação de sementes de Pimenta-de-macaco (Piper aduncum L.) submetidas ao estresse hídrico. Belém-PA. In: CONGRESSO BRASILEIRO DE OLERICULTURA, 46., 2006, Goiânia, Anais... Goiânia: Associação Brasileira de Horticultura, 2006.

MAGUIRE, J.D. Speed of germination-aid in selection and evaluation for seedling emergence and vigor. Crop Science, v.2, n.1, p.176-177, 1962.

MAIA, J.G.S.; ZOHHBI, M. das G.B.; ANDRADE, E.H.A.; SANTOS, A.S.; SILVA, M.H.L. da; LUIZ, A.I.R.; BASTOS, C.N. Constituents of the essential oil of L. growing wild in the Amazon region. Flavour and Fragance Journal, v.13, p.269-272, 1998 .

MARCOS FILHO, J. Fisiologia de sementes de plantas cultivadas. Piracicaba: FEALQ, 1.ed. 2005. 495p.

NISSEN, O. MSTAT-C. A microcomputer for desing, management and analysis of agronomic research experiments. Version 2.11 East Lansing: Michigan State University, p.300, 1993.

PIMENTEL, F.A.; PINHEIRO, P.S.N. Mapeamento e 
caracterização de habitats naturais de pimenta longa (Piper hispidinervum) no município de Brasiléia. Rio Branco, AC: Embrapa Acre, 2000. 20p. (Embrapa Acre. Boletim de Pesquisa, 28).

PIMENTEL, F.A.; SOUSA, M. de M.M.; SÁ, C.P. de; CABRAL, W.G.; SILVA, M.R. da; PINHEIRO, P.S.N.; BASTOS, R.M. Recomendações básicas para o cultivo da pimenta longa (Piper hispidinervium) no Estado do Acre. Rio Branco: Embrapa Acre, 1998, 14p. (Embrapa Acre. Circular Técnica, 28).

REGO, S.S.; NOGUEIRA, A.C.; KUNIYOSHI, Y.S.; SANTOS, A.F. Germinação de sementes de Blephacoralyx salicifolius (H. B. K.) Berg. Em diferentes substratos e condições de temperatura, luz e umidade. Revista Brasileira de Sementes, v.31, n.2, p.212-220, 2009.

STEFANELO, R.; GARCIA, D.C.; MENEZES, N.L.; MUNIZ, M.F.B.; WRASSAE, C.F. Efeito da luz, temperatura e estresse hídrico no potencial fisiológico de sementes de funcho. Revista Brasileira de Sementes, v.28, n.2, p.135$141,2006$.
WADT, L.H. de O. Estrutura genética de populações naturais de pimenta longa (Piper hispidinervum C. DC.) visando seu uso e conservação. 2001. 95f. Tese (Doutorado em Agronomia - Genética e melhoramento de plantas) Curso de pós-graduação em Agronomia, Escola Superior de Agricultura "Luiz de Queiroz", Universidade de São Paulo, Piracicaba, 2001.

WADT, P.G.S.; PACHECO, E.P. Efeito da adubação nitrogenada, em diferentes densidades de plantio, na produção de biomassa de Pimenta Longa (Piper hispidinervum C. DC.). Revista de Biologia e Ciência da Terra, v.6, n.2, p.334-340, 2006.

YAMASHITA, O.M.; ALBUQUERQUE, M.C.F.; GUIMARÃES, S.C.; SILVA, J.L.; CARVALHO, M.A.C. Influência da temperatura e da luz na germinação de sementes de couve-cravinho (Porophyllum ruderale (Jacq.) Cass). Revista Brasileira de Sementes, v.30, n.3, p.202206, 2008.

ZUCARELI, V.; FERREIRA, G.; AMARO, A.C.E.; ARAUJO, F.P. Fotoperíodo, temperatura e reguladores vegetais na germinação de Passiflora cincinnata Mast. Revista Brasileira de Sementes, v.31, n.3, p.106-114, 2009. 